\title{
28 Research Square \\ Health-Related Quality of Life of Military Policemen in Salvador, Brazil: Cross-Sectional Study.
}

\section{Carla Requião Barreto}

Federal University of Bahia: Universidade Federal da Bahia

\section{Fernando Martins Carvalho}

Federal University of Bahia: Universidade Federal da Bahia

Liliane Lins-Kusterer ( $\square$ lkusterer@gmail.com )

Faculty of Medicine Federal University of Bahia https://orcid.org/0000-0003-3736-0002

\section{Research}

Keywords: Police, Quality of life, Work Capacity Evaluation, Cross-sectional studies.

Posted Date: September 22nd, 2020

DOI: https://doi.org/10.21203/rs.3.rs-75423/v1

License: (c) (i) This work is licensed under a Creative Commons Attribution 4.0 International License. Read Full License 


\section{Abstract}

Background: Brazil is a violent society and police officers play a fundamental role in this scenario. Police work is a stressful occupation. Dealing with routine violence, police officers must have high standards of physical and mental health. Patrolling the streets involves several risks and stressful situations that may hamper military policemen's quality of life. This study aimed to identify factors associated with health-related quality of life in military policemen.

Methods: A cross-sectional design study investigated a random sample of 329 male military police officers, engaged in patrolling the streets of Salvador, Bahia, Brazil. A structured questionnaire was applied to the policemen during their working hours. Information was collected about age, education, marital status, housing, car ownership, police rank, working day, alcohol consumption, smoking, frequency of vigorous physical activity and weight and height, in order to calculate body mass index. Health-related quality of life was evaluated through the 36-Item Short Form Survey Questionnaire (SF-36). Work ability was assessed through the Work Ability Index questionnaire. Poor work ability was defined by a Work Ability Index 727 points. Multivariable linear regression models were used to measure the impact of police officer characteristics on variation in the Physical Component and Mental Component Summary scores.

Results: Normalised scores were below 50.0 for seven out of the eight SF-36 domains and for the two component summaries. The SF-36 Physical Component Summary was associated with poor work ability, while the Mental Component Summary was associated with poor work ability, excessive alcohol consumption, and younger age. Poor work ability affected $10.3 \%$ of the workforce. Decreases of 7.363 units (\%) in the Physical Component Summary mean and of 12.862 units (\%) in the Mental Component Summary mean were estimated for policemen with poor work ability.

Conclusions: The military police officers investigated presented poor health-related quality of life, associated with younger age, excessive alcohol consumption, and poor work ability, which may hamper the performance of their professional activities.

\section{Background}

During the Vietnam War, between 1955 and 1975, 47,406 American soldiers were killed in action or captivity [1]. In Brazil, in 2018 alone, 57,358 intentional violent deaths were recorded, corresponding to 27.5 deaths per 100,000 inhabitants. Eleven out of 100 deaths were caused by police officers. Conversely, 343 policemen were killed, $256(75 \%)$ of these deaths occurred outside working hours [2].

As other latin american countries, Brazil is a violent society and police officers play a fundamental role in this scenario. Police work is a stressful occupation. Dealing with routine violence, police officers must have high standards of physical and mental health, which usually deteriorate over time [3]. Patrolling the streets involves dealing with theft, drug-trafficking, criminal behaviour, long working hours, the possibility of being injured or killed, and other stressful situations that may damage their physical [4] and mental health [5].

This study aimed to identify factors associated with the health-related quality of life (HRQoL) of military policemen in the city of Salvador, in the state of Bahia, Brazil.

\section{Methods}

We conducted a cross-sectional study of factors associated with health-related quality of life in a representative sample of military policemen from Salvador, Bahia, Brazil. The accessible population was composed of all the 3,500 military police officers from 27 battalions. The study included only males, engaged in visible patrolling in public spaces in the city, and excluded those who were on medical leave, engaged in administrative functions, or in specific situations not related to their 
core-activity. This study is part of a larger study that evaluated other health aspects in military police officers from Salvador [6].

Between February and April 2014, a trained researcher applied an individual, structured questionnaire to the policemen during their working hours. Information was collected about age, education, marital status, housing, car ownership, police rank, working day, alcohol consumption, smoking, frequency of vigorous physical activity and weight and height, in order to calculate body mass index. Obesity was defined as body mass index $\geq 30.0$ [7]. The policeman's own perception of their work ability was measured by the Work Ability Index - WAI [8]. The Work Ability Index questionnaire has been translated [9] and validated for the Brazilian population, with satisfactory construct validity and reliability [10] and test-retest reliability [11]. WAI has seven dimensions: current work ability compared to lifetime best (0-10 points), work ability in relation to demands of the job (2-20 points), number of diseases diagnosed by a physician (1-7 points), estimated work impairment due to diseases (1-6 points), sick leave over the past 12 months (1-5 points), own prognosis of work ability 2 years from now (1-7 points), and mental resources (1-4 points). The WAI index is calculated through the sum of points over the seven dimensions, varying from 7 to 49 points. The score can be classified according to four work ability categories: poor (7-27 points), moderate (28-36 points), good (37-43 points), and excellent (44-49 points) [12]. For the purposes of this study, poor work ability was codified as Yes (WAI 7-27 points) or No (WAI 28-49 points). Health-related quality of life was evaluated using the 36-Item Short Form Survey (SF-36) [13].

We selected a random sample, proportionally stratified by the 27 battalions. As recommended by the SF-36 manual [14], we used Cohen's formula [15] to calculate a sample size capable of detecting differences of 5.0 points between the sample mean and the mean of a fixed standard. To estimate the population's standard deviations, we adopted the values for males aged 25-34, 35-44, and 44-54 years old, as demonstrated in Table 10.3 of the SF-36 manual [14]. We used the value 30.24, related to the Role Physical domain, for men aged 44-54 years, since this was the largest of the three age groups and the eight SF-36 domains. The estimated minimal sample size was $n=289$, but this was deliberately inflated by $20 \%$, resulting in a desired sample size of $n=347$ policemen. There were no refusals, however 18 individuals returned questionnaires with incomplete answers and were excluded from the study. The final sample size was composed of 329 policemen.

\section{Data processing and analysis}

Based on answers to the SF-36 questionnaire, eight multi-item scales (physical functioning, role limitations due to physical problems, bodily pain, general health perceptions, vitality, social functioning, role limitations due to emotional problems and mental health) were constructed and subsequently aggregated into two Component Summaries: the Physical Component Summary and the Mental Component Summary. The eight scales were scored using raw data (0 to 100 algorithms), while the respective normalized scores and the scores for the two summary measures was performed using QualityMetric Health Outcomes $^{\mathrm{TM}}$ Scoring Software 4.0 [16]. The study was licensed by QualityMetric Health Outcomes ${ }^{\mathrm{TM}}$ under number QM025904. The normalization procedure transforms raw scores into a mean of 50 and a standard deviation of 10, taking the United States of America general population as a reference. This transformation achieves the same mean and standard deviation for all SF-36 scales and summary measures. Because of their comparable variance, normalized scores enable comparisons between the respective domain and the component scales. Higher scores represent better health-related quality of life.

The internal consistency of the SF-36 domains was evaluated using Cronbach's alpha. Values should exceed .70, but values $\geq 0.60$ are acceptable in exploratory research [17].

Bivariate analyses used t-tests to compare means from the independent samples. Multivariable linear regression models were used to measure the impact of police officer characteristics on variation in the Physical Component and Mental Component Summary scores. All prediction variables were inserted as a block in each equation, using the default selection method 'Enter'. Cases presenting studentized residual analysis varying around \pm 3.000 standard deviations were identified as outliers. Data were analysed using SPSS version 20.0 (IBM Corp., Armonk, NY, USA).

Page $3 / 10$ 
All randomly selected policemen participated voluntarily in the survey. After explaining the objectives, participants signed a free informed consent form. All information related to the participants was confidential. The study was approved by the Ethics Committee in Research on Human Beings of the Medical School of Bahia for opinion number 554,724.

\section{Results}

Normalised scores were below 50.0 for the eight SF-36 domains and the two component summaries, except for vitality $(51.8 \pm 10.7)$. Scores for general health $(44.6 \pm 7.8)$ and social functioning $(43.9 \pm 11.1)$ were particularly low. The internal reliability indices for each domain, measured by Cronbach's alpha coefficient, varied from 0.624 (General Health) to 0.896 (Physical Functioning) (Table 1).

Table 1

SF-36 normalized scores (in \%) and respective Cronbach's alpha coefficients of 329 military policemen.

\begin{tabular}{|lll|}
\hline SF-36 & Mean \pm sd & Cronbach's alpha \\
\hline Physical Functioning (PF) & $49.8 \pm 8.6$ & 0.896 \\
\hline Role Physical (RP) & $46.0 \pm 10.7$ & 0.815 \\
\hline Bodily Pain (BP) & $47.4 \pm 11.3$ & 0.863 \\
\hline General Health (GH) & $44.6 \pm 7.8$ & 0.624 \\
\hline Vitality (VT) & $51.8 \pm 10.7$ & 0.866 \\
\hline Social Functioning (SF) & $43.9 \pm 11.1$ & 0.743 \\
\hline Role Emotional (RE) & $45.4 \pm 12.3$ & 0.828 \\
\hline Mental Health (MH) & $47.2 \pm 12.0$ & 0.856 \\
\hline Physical Component Summary (PCS) & $47.9 \pm 8.2$ & - \\
\hline Mental Component Summary (MCS) & $46.4 \pm 11.7$ & - \\
\hline
\end{tabular}

The policemen in the study were predominantly married (61.1\%), presented low levels of education (64.4\%), were soldiers (92.4\%), owned a car (70.2\%), and worked $>8$ hours/day (79.6\%). They did not practice vigorous physical activity frequently (47.7\%), and some were obese (14.3\%), smokers (5.8\%), heavy drinkers (7.3\%), and presented poor work ability (10.3\%). Bivariate analyses revealed that the Physical Component Summary was strongly $(\mathrm{P}<0.05$ or less) associated with working day $(P=0.021)$, vigorous physical activity $(P=0.047)$, obesity $(P=0.043)$, and poor work ability $(P<0.001)$. The Mental Component Summary was strongly associated with excessive alcohol consumption $(P=.002)$ and poor work ability $(P<$ 0.001) (Table 2). 
Table 2

Physical (PCS) and Mental (MCS) Component Summaries scores (\%) according to characteristics of military policemen.

\begin{tabular}{|c|c|c|c|c|c|c|c|c|}
\hline \multirow[t]{2}{*}{ Characteristic } & \multirow[t]{2}{*}{$\mathbf{N}$} & \multirow[t]{2}{*}{$\%$} & \multicolumn{3}{|l|}{ PCS } & \multicolumn{3}{|l|}{ MCS } \\
\hline & & & mean & sd & $\mathrm{P}^{\mathrm{a}}$ & mean & sd & $\mathrm{P}^{\mathrm{a}}$ \\
\hline Education & & & & & 0.916 & & & 0.263 \\
\hline High school & 212 & 64.4 & 48.0 & 7.9 & & 46.9 & 11.4 & \\
\hline Graduated/post grad. & 117 & 35.6 & 47.9 & 8.8 & & 45.4 & 12.0 & \\
\hline Marital status & & & & & 0.746 & & & 1.000 \\
\hline Married & 201 & 61.1 & 47.8 & 8.2 & & 46.5 & 12.0 & \\
\hline Others & 128 & 38.9 & 48.1 & 8.2 & & 46.1 & 11.2 & \\
\hline Police rank & & & & & 0.268 & & & 0.837 \\
\hline Officer & 25 & 7.6 & 49.7 & 7.2 & & 46.8 & 12.2 & \\
\hline Soldier & 304 & 92.4 & 47.8 & 8.3 & & 46.3 & 11.6 & \\
\hline Income & & & & & 0.094 & & & 0.239 \\
\hline 2-6 min. Wages & 298 & 90.6 & 47.7 & 8.3 & & 46.1 & 11.7 & \\
\hline$>6$ min. Wages & 31 & 9.4 & 50.3 & 7.2 & & 48.7 & 11.6 & \\
\hline Car ownership & & & & & 0.107 & & & 0.075 \\
\hline Yes & 231 & 70.2 & 48.4 & 7.8 & & 47.1 & 11.3 & \\
\hline No & 98 & 29.8 & 46.8 & 9.1 & & 44.6 & 12.3 & \\
\hline House ownership & & & & & 1.000 & & & 0.466 \\
\hline Yes & 108 & 32.8 & 47.9 & 9.0 & & 47.0 & 11.6 & \\
\hline No & 221 & 67.2 & 47.9 & 7.9 & & 46.0 & 11.7 & \\
\hline Working day & & & & & 0.021 & & & 0.453 \\
\hline$\leq 8 \mathrm{~h} /$ day & 67 & 20.4 & 50.0 & 7.6 & & 47.3 & 10.7 & \\
\hline$>8$ h/day & 262 & 79.6 & 47.4 & 8.3 & & 46.1 & 11.9 & \\
\hline Vigorous physical activity & & & & & 0.047 & & & 0.486 \\
\hline Up to 2 times/week & 157 & 47.7 & 47.0 & 7.9 & & 45.9 & 12.0 & \\
\hline 3-7 times/week & 172 & 52.3 & 48.8 & 8.4 & & 46.8 & 11.4 & \\
\hline Body mass index & & & & & 0.043 & & & 0.828 \\
\hline Normal/Overweight & 282 & 85.7 & 48.4 & 7.8 & & 46.4 & 11.8 & \\
\hline Obese & 47 & 14.3 & 45.2 & 10.1 & & 46.0 & 11.1 & \\
\hline Smoking & & & & & 0.152 & & & 0.856 \\
\hline No/Ex-smoker & 310 & 94.2 & 48.1 & 8.2 & & 46.4 & 11.6 & \\
\hline
\end{tabular}

a - Independent samples t-test. 


\begin{tabular}{|lccccccccc|}
\hline Characteristic & N & \% & PCS & \multicolumn{5}{c|}{ MCS } & \\
\cline { 5 - 10 } & & & mean & sd & Pa & mean & sd & $\mathbf{P a}^{\mathbf{a}}$ \\
\hline Smoker & 19 & 5.8 & 45.3 & 9.2 & & 45.9 & 12.4 & \\
\hline Alcohol consumption & & & & & 0.066 & & & 0.002 \\
\hline None/Light & 305 & 92.7 & 48.2 & 8.1 & & 46.9 & 11.5 & \\
\hline Excessive & 24 & 7.3 & 45.0 & 9.0 & & 39.4 & 11.3 & \\
\hline Poor Work Ability & & & & & $<0.001$ & & & $<0.001$ \\
\hline No & 295 & 89.7 & 48.8 & 7.9 & & 47.7 & 10.7 & \\
\hline Yes & 34 & 10.3 & 40.6 & 7.1 & & 34.6 & 13.0 & \\
\hline a - Independent samples t-test. & & & & & & & \\
\hline
\end{tabular}

The simple linear regression coefficient for age (in years) and Physical Component Summary provided B $=-0.110(P=$ 0.081), while for the Mental Component Summary $B=0.227(P=0.011)$.

Multiple linear regression analyses revealed that the Physical Component Summary was associated with poor work ability $(\mathrm{P}<0.001)$. Equation 1 estimates that the mean Physical Component Summary was 7.363 units $(\%)$ lower among those with poor work ability. Equation 2 revealed that the Mental Component Summary was associated with poor work ability $(P<$ 0.001), excessive alcohol consumption $(P=0.028)$, and age $(P=0.011)$. Equation 2 estimates that the mean Mental Component Summary was 12.862 units (\%) lower among those with poor work ability and 5.354 lower among heavy drinkers (Table 3).

Beta (standardized) regression coefficients enable comparisons of the relative effect of each independent variable on the model's dependent variables. Compared to the other twelve variables in the models, poor work ability presented the highest betas in both Equation 1 (-0.274) and Equation 2 (-0.337) (Table 3).

Residual analysis revealed one outlier in Equation 1 (with PCS as the dependent variable), and two outliers in Equation 2 (with MCS as the dependent variable). Excluding these outliers did not substantially change the results in either equation. Collinearity among the predictors did not provide important limitations to the analyses. Tolerance collinearity statistics (1 $R^{2}$ ) were always high for Equation 1, ranging from 0.486 to 0.956 , as well as for Equation 2, ranging from 0.486 to 0.956 . Adjusted $\mathrm{R}^{2}$ was 0.094 in Equation 1 and 0.132 in Equation 2 (Table 3). 
Table 3

Multiple linear regression equations having PCS and MCS (\%) as dependent variable in 329 military policemen.

\begin{tabular}{|c|c|c|c|c|c|c|c|c|}
\hline \multirow{2}{*}{$\begin{array}{l}\text { Predictor in the } \\
\text { equation (referent) }\end{array}$} & \multicolumn{4}{|c|}{ Equation 1 (Dependent = PCS) } & \multicolumn{4}{|c|}{ Equation 2 (Dependent = MCS) } \\
\hline & $\begin{array}{l}\text { Regression } \\
\text { coeff. b }\end{array}$ & $\begin{array}{l}\text { Std } \\
\text { error } \\
\text { of b }\end{array}$ & $\mathbf{P}$ & $\begin{array}{l}\text { Standardized } \\
\text { coeff. Beta }\end{array}$ & $\begin{array}{l}\text { Regression } \\
\text { coeff. b }\end{array}$ & $\begin{array}{l}\text { Std } \\
\text { error } \\
\text { of } b\end{array}$ & $\mathbf{P}$ & $\begin{array}{l}\text { Standardized } \\
\text { coeff. Beta }\end{array}$ \\
\hline $\begin{array}{l}\text { Education } \\
\text { (Grad/Postgrad.) }\end{array}$ & -0.203 & 0.942 & 0.830 & -0.012 & -0.006 & 1.310 & 0.996 & 0.000 \\
\hline $\begin{array}{l}\text { Marital status } \\
\text { (Married) }\end{array}$ & -0.620 & 0.936 & 0.508 & -0.037 & 0.073 & 1.301 & 0.955 & 0.003 \\
\hline Police rank (Officer) & 1.522 & 2.331 & 0.514 & 0.049 & 2.140 & 3.240 & 0.509 & 0.049 \\
\hline $\begin{array}{l}\text { Income (> } 6 \text { min. } \\
\text { Wages) }\end{array}$ & -2.630 & 2.083 & 0.208 & -0.094 & -3.029 & 2.896 & 0.296 & -0.076 \\
\hline Car ownership (Yes) & -0.767 & 0.988 & 0.438 & -0.043 & -1.588 & 1.373 & 0.248 & -0.062 \\
\hline $\begin{array}{l}\text { Housing ownership } \\
\text { (Yes) }\end{array}$ & 0.277 & 0.944 & 0.770 & 0.016 & 0.346 & 1.313 & 0.792 & 0.014 \\
\hline $\begin{array}{l}\text { Working day ( } \leq \\
8 \mathrm{~h} / \text { day) }\end{array}$ & -1.164 & 1.135 & 0.306 & -0.057 & 0.286 & 1.578 & 0.856 & 0.010 \\
\hline $\begin{array}{l}\text { Vigorous physical } \\
\text { activity ( } 3-7 \\
\text { times/week) }\end{array}$ & -1.303 & 0.881 & 0.140 & -0.079 & -0.634 & 1.225 & 0.605 & -0.027 \\
\hline $\begin{array}{l}\text { Obese } \\
\text { (Normal/Overweight) }\end{array}$ & -1.440 & 1.309 & 0.272 & -0.062 & 0.700 & 1.819 & 0.701 & 0.021 \\
\hline Age (years) & -0.076 & 0.067 & 0.255 & -0.067 & 0.237 & 0.093 & 0.011 & 0.147 \\
\hline $\begin{array}{l}\text { Smoking (No/Ex- } \\
\text { smoker) }\end{array}$ & -1.256 & 1.914 & 0.512 & -0.036 & 0.525 & 2.659 & 0.844 & 0.011 \\
\hline $\begin{array}{l}\text { Excessive alcohol } \\
\text { consumption } \\
\text { (None/Light) }\end{array}$ & -1.231 & 1.746 & 0.481 & -0.039 & -5.354 & 2.427 & 0.028 & -0.120 \\
\hline $\begin{array}{l}\text { Poor Work Ability } \\
\text { (No) }\end{array}$ & -7.363 & 1.483 & $<.001$ & -0.274 & -12.862 & 2.060 & $\begin{array}{l}< \\
0.001\end{array}$ & -0.337 \\
\hline Constant & 54.789 & 3.025 & $<0.001$ & - & 40.334 & 4.205 & $<0.001$ & - \\
\hline
\end{tabular}

\section{Discussion And Conclusion}

General health and social functioning scores were particularly low for policemen in Salvador. All eight SF-36 scales contributed, with varying weights, to the Physical Component and Mental Component Summary scores. However, physical functioning, role physical, and bodily pain usually contributed more significantly to the Physical Component Summary, whereas social functioning, role emotional, and mental health contributed more significantly to the Mental Component Summary. The vitality, general health, and social functioning scales provided noteworthy contributions to both Physical and Mental Component Summary scores [18].

Reliability was high (>0.80) for most of the SF-36 domains (PF, RP, BP, VT, RE and MH); good (0.743) for the SF domain, and acceptable (0.642) for the GH domain. 
The Physical $(P<0.001)$ and Mental $(P<0.001)$ Component Summaries of the health-related quality of life of the study population presented strong associations with poor work ability. The Work Ability Index is a complex construct that represents interaction between the individual's resources and their physical, mental and social work demands, the work environment, organizational culture and management. The WAI may be affected by various aspects of a worker's healthrelated quality of life [12]. Analogously, the SF-36 physical and mental component summaries are also complex constructs that involve a range of aspects related to work ability. Significant relationships were reported between WAI score and all SF36 dimensions $[19,20]$.

Compared to the other twelve variables in the models, poor work ability presented the best predictors of the physical and mental component summaries, by some distance. We estimated a decrease of 7.363 units (\%) in the PCS mean and a decrease of 12.862 units (\%) in the MCS mean among policemen with poor work ability. The great majority of these decreases reflect poorer physical and mental health-related quality of life for a policemen with poor work ability.

Minimal Clinically Important Difference (MCID) can be defined as the smallest difference in score in the domain of interest which is perceived to be beneficial or harmful, and that would imply in a change in patient's management. Ideally, the MCID should be ascertainded to each particular study population [21]. The MCID for group-level is necessarily smaller than for individual patient-level, because of greater measurement error inherent to patient's quality of life scores [22]. To the best of our knowledge, the MCID for the SF-36 Component Summaries (PCS and MCS) have not yet been determined for general or occupational populations, like military policemen.

It is unacceptable for $10.3 \%$ of these military policemen to present poor work ability. Policemen should be physically fit in order to undertake patrols. The situation is even more worrisome when we consider that poor work ability is strongly associated with a lower mental health component in their health-related quality of life.

Policemen who were heavy drinkers presented MCS scores 5.354 lower than those who did not drink alcohol or were light drinkers. The inherently stressful work in the police service may be an important contributor to alcohol use. Excessive alcohol consumption is a frequent problem among a number of occupational groups in the USA, such as miners (17.5\%) and construction workers (16.5\%), aged between 18 and 64 [23]. In a large survey among male police officers from California and New York City, 7.8\% met criteria that indicated probable lifetime alcohol abuse or dependence [24]. This figure is similar to that found for the self-reported excessive alcohol consumption in our study: $7.3 \%$.

Multiple regression analysis revealed a positive, statistically significant $(b=0.237 ; P=0.011)$ association between age and the mental component of health-related quality of life (MCS). This association probably reflects a healthy worker survivor effect [25]. Stressful working conditions can affect policemen's mental health status over time, leading them to choose to leave the workforce, while those presenting optimal physical and mental health tend to remain in the job.

Some limitations of this study need to be addressed. Its cross-sectional design precludes the possibility of establishing causality among our key variables, mainly because of a lack of knowledge about their temporal sequence. Bi-directional cause-effect relationships between HRQoL component summaries (PCS and MCS) and poor work ability cannot be ruled out. Despite these limitations, this pioneering study was the first to evaluate the HRQoL of military policemen in a representative sample from a large city in Brazil. The physical and mental components of HRQoL were strongly associated with poor work ability. The mental component of HRQoL was lower among heavy drinkers and those who were younger. Given the key role military policemen play in community safety, these results are worrisome and deserve the attention of military police corporate managers in order to take preventive measures to protect these workers' health. Indeed, the results of this study provided valuable information to the military corporation health department to plan and establish its first Medical Control Program [26].

In conclusion, military police officers from Salvador city presented poor health-related quality of life, associated with excessive alcohol consumption and poor work ability, which may hamper their professional activities. The association

Page $8 / 10$ 
between younger age and lower mental component of their health-related quality of life (MCS) is probably due to a healthy worker survivor effect. These findings were important in planning the activities of a health care program for this particularly vulnerable occupational group.

\section{Declarations}

Ethical approval and consent to participate: The study was approved by the Ethics Committee in Research on Human Beings of the Medical School of Bahia for opinion number 554,724. All policemen participated voluntarily in the survey and signed a free informed consent form.

Consent for publication: Not applicable.

Availability of data and materials: The data supporting the findings of this study are available from Liliane Lins-Kusterer but restrictions apply to the availabilityof these data, which were used under license for the current study, and so are not publicly available. Data are however available from the authors upon reasonable request and with permission of Liliane Lins-Kusterer.

Competing interests: The authors declare that they have no competing interests.

Funding: Brazilian National Council for Scientific and Technological Development (CNPq). A researcher fellowship grant number 304691/2018-6 on behalf of Fernando M. Carvalho.

Authors' contributions: Carla Barreto and Liliane Lins-Kusterer have worked in the conception of the study. Carla Barreto worked in data collection and wrote the first draft. Carla Barreto, Fernando Carvalho, and Liliane Lins-Kusterer have worked on the design of the study, data analysis and interpretation, wrote and critically reviewed successive drafts of the manuscript and approved its last version for publication.

\section{References}

1. Military Factory. Vietnam War Casualties (1955-1975) (2020). [Internet] Military Factory. [cited 2020 Jan 30] Available from: https://www.militaryfactory.com/vietnam/casualties.asp

2. Fórum Brasileiro de Segurança Pública (2019) Anuário Brasileiro de Segurança Pública 2019. São Paulo; Fórum Brasileiro de Segurança Pública. http://www.forumseguranca.org.br/wp-content/uploads/2019/10/Anuario-2019FINAL_21.10.19.pdf Acessed 17 January 2020. [Portuguese]

3. Silva FC, Hernandez SSS, Arancibia BAV, Castro TLS, Gutierres-Filho, PJB, Silva R. Health-related quality of life and related factors of military police officers. Health Qual Life Outcomes 2014; 12:60. https://doi.org/doi: 10.1186/14777525-12-60.

4. Sörensen L, Smilander J, Louhervaara V, Korhonern O, Oja P. Physical activity, fitness and body composition of Finnish police officers: a 15-year follow-up stydy. Occup Med 2000; 5:3-10. https://doi.org/1093/occmed/50.1.3

5. Chen HC, Chou FH, Chen MC, Su SF, Wang SY, Feng WW, et al. A survey of quality of life and depression for police officers in Kaohsiung, Taiwan. Qual Life Res 2006; 15:925-932. https://doi.org/1007/s11136-005-4829-9

6. Barreto CR, Lins-Kusterer L, Carvalho, FM. Work ability of military police officers. Rev Saude Publica, 2019; 53,79. http://www.scielo.br/pdf/rsp/v53/1518-8787-rsp-53-79.pdf

7. World Health Organization. Obesity: preventing and managing the global epidemic. Report of a WHO Consultation. Geneva: WHO; WHO Technical Report Series, 894, 2000. Available from: http://www.who.int/nutrition/publications/obesity/WHO_TRS_894/en/

8. Ilmarinen The Work Ability Index. Occup Med 2007; 57,160. https://doi.org/10.1093/occmed/kqm008 
9. Tuomi K, Ilmarinen J, Jahkola A, Katajarinne L, Tulkki A. Índice de capacidade para o trabalho. São Carlos: EdUFSCar., 2005 [Portuguese]

10. Martinez MC, Latorre MRDO, Fischer FM. Validity and reliability of the Brazilian version of the Work Ability Index questionnaire. Rev Saude Publica 2009; 43(3):525-532. http://dx.doi.org/10.1590/S0034-89102009005000017

11. Renosto A, Biz P, Hennington EA Pattussi MP. Confiabilidade teste-reteste do Índice de Capacidade para o Trabalho em trabalhadores metalúrgicos do Sul do Brasil. Rev Bras Epidemiol 2009; 12(2):217-225. https://doi.org/10.1590/S1415790X2009000200011 [Portuguese]

12. Gould R, Ilmarinen J, Järvisalo J, Koskinen S (eds.). Dimensions of work ability. Results of the health 2000 survey. Vaasa: Finnish Centre for Pensions. 2008 https://www.researchgate.net/publication/228485936_Dimensions_of_Work_Ability Accessed 17 January 2020. SF health Surveys.

13. Optum: 2020 [Internet]. Optum. [cited 2020 Jan 30] Available from: https://www.optum.com/solutions/lifesciences/answer-research/patient-insights/sf-health-surveys.html

14. Ware Jr. JE, Snow KK, Kosinski M, Gandek B. SF-36 Health Survey. Manual and Interpretation Guide. 1993 (Table 7.8, page 7:12) Boston: Nimrod Press.

15. Cohen J. Statistical power for the behavioral sciences. Hillsdale, NJ: Lawrence Earlbaum Associates, 1988.

16. Saris-Baglama RN, Dewey CJ, Chisholm GB, Plumb E, King J, Rasicot P, et al. QualityMetric Health OutcomesTM Scoring Software 4.0. Lincoln, Rl: QualityMetric Incorporated. 2010.

17. Hair JF, Black WC, Babin BJ, Anderson RE. Multivariate data analysis. Seventh edition. Harlow: Pearson Education, Inc. 2014.

18. Ware Jr. JE. SF-36 health survey update. Spine 2000; 25(24):3130-3139. https://doi.org/10.1097/00007632200012150-00008

19. Abdolalizadeh M, Arastoo AA, Ghsemzadeh R, Montazeri A, Ahmad, K, Azizi A. The psychometric properties of an Iranian translation of the Work Ability Index (WAI) questionnaire. J Occup Rehabil 2012; 22(3):401-408. https://doi.org/1007/s10926-012-9355-3.

20. Martinez MC, Latorre MRDO. Health and work ability among office workers. Rev Saude Publica2006; 40(5):851858. https://dx.doi.org/10.1590/S0034-89102006000600015

21. King MT. A point of minimal important difference (MID): a critique of terminology and methods. Expert Rev Pharmacoecon Outcomes Res 2011; 11:171-184. https://doi.org/1586/erp.11.9

22. Yost KJ, Eton DT. Combining distribution- and anchor-based approaches to determine minimally important differences: the FACIT experience. Eval Health Prof 2005; 28:172-191. https://doi.org/10.1177/0163278705275340

23. Bush DM, Lipari RN. The CBHSQ Report: Substance Use and Substance Use Disorder, by Industry. Rockville, MD: Center for Behavioral Health Statistics and Quality. 2015.

https://www.samhsa.gov/data/sites/default/files/report_1959/ShortReport-1959.pdf

24. Ballenger JF, Best SR, Metzler TJ, Wasserman DA, Mohr DC, Liberman A, et al. Patterns and predictors of alcohol use in male and female urban police officers. Am J Addict 2011; 20(1):21-29. https://doi.org/1111/j.1521-0391.2010.00092.x

25. Chowdhury R, Shah D, Payal AR. Healthy worker effect phenomenon: Revisited with emphasis on statistical methods A review. Indian J Occup Environ Med 2017; 21(1):2-8. http://doi.org/10.4103/ijoem.IJOEM_53_16

26. Polícia Militar da Bahia. Subcomando Geral. Portaria 047 de 18 de junho de 2014. Institui o Programa de Controle Médico - PCM na PMBA, e dá outras providências. Salvador: PMBA, 22 pag. 